\title{
Dollarization and inflation in a two-country optimization model
}

\author{
HENG-FU ZoU* \\ Policy Research Department, The World Bank, Washington DC 20433, USA
}

\begin{abstract}
In a two-country, two-currency model, this paper examines the conditions of dollarization, analyzes the effect of government inflation finance and studies the strategic interdependence of different-currency inflation. (JEL F30).
\end{abstract}

As in Ortiz (1983), dollarization here measures the degree of shift from using domestic currency toward foreign money as a legal tender. For obvious reasons, we take foreign money as the dollar. Many existing studies such as Fischer (1982, 1983 ) and Lamdany and Dorlhiac (1987) have focused on the country experiencing dollarization. In our study, we assume that there are two countries in the world: the USA and LA (which stands for Latin America); the dollar is the currency of the USA and the peso is the currency of LA; and dollarization is going on only in LA. In Section I we will set up a two-country optimization model for the representative families in the USA and LA and discuss the conditions for dollarization in LA under the assumption that the government in LA distributes its inflation tax to the public through lump-sum transfers. In Section II, we introduce government inflation finance in LA into the model and present a coherent, general equilibrium model for the determination of both peso and dollar inflation rates. The conditions for dollarization and the strategic choices of the peso and dollar inflation rates by the governments will be analyzed in detail. We summarize our main findings in Section III.

\section{Currency substitution in LA and dollarization}

We assume that there is free trade between the USA and LA and there is one homogeneous good with price $p$. A representative family in LA derives instantaneous utility from consumption and the liquidity services of real balances. With currency substitution in LA, both LA's peso and the US dollar provide liquidity services. Following Stockman (1978) and Liviatan (1981), we assume

\footnotetext{
* I am grateful to Jeffrey Sachs for encouraging me to write this paper and for helpful discussion. I thank an anonymous referee, Maxim Engers, and especially Michael Melvin for many suggestions and help on revising this paper. Responsibility for the contents of this paper is solely mine and not that of the World Bank.
} 
that the preference of the representative family in LA is functionally separable in per capita consumption and the real balances:

$$
U\left(c^{*}, m^{*}, m_{f}\right)=U\left(c^{*}\right)+V\left(m^{*}, E m_{f}\right),
$$

where all variables are in real terms, and $c^{*}$ is per capita consumption, $m^{*}$ is per capita peso holdings, $m_{f}$ is per capita dollar holdings, and $E$ is the exchange rate; $U($.$) and V($.$) are increasing and concave in c^{*}, m^{*}$, and $m_{f}$.

Free trade between the USA and LA and one homogeneous good in the whole world market make it plausible to assume purchasing power parity:

$$
p^{*}=E p,
$$

where $p^{*}$ is the price of consumption goods denominated in pesos.

With two kinds of currencies in the portfolio of the representative family in LA, the per capita real asset in terms of pesos is the sum of these two currencies divided by the peso price:

$$
a^{*}=\left(M^{*} / p^{*} N^{*}\right)+\left(M / p^{*} N^{*}\right)=m^{*}+E M / p N^{*}=m^{*}+E m_{f},
$$

where $N^{*}$ is the population in LA. For simplicity we let the population growth rates in both the USA and LA equal zero.

We might as well assume that the initial exchange rate $E$ is equal to one, then

$$
a^{*}=m^{*}+m_{f} .
$$

The typical family in LA maximizes a discounted utility over an infinite horizon subject to the budget constraint:

$$
\begin{aligned}
& \operatorname{Max} \int_{0}^{\infty}\left[U\left(c^{*}\right)+V\left(m^{*}, m_{f}\right)\right] e^{-\rho^{*} t} d t \\
& \text { s.t. } a^{*}=y^{*}+x^{*}-c^{*}-\pi m_{f}-\pi^{*} m^{*}, \\
& \quad a^{*}=m_{f}+m^{*},
\end{aligned}
$$

where $\rho^{*}$ is the time discount rate, $y^{*}$ is per capita real income, $x^{*}$ is the LA government's transfer to its citizens, $\pi$ is the expected dollar inflation rate, $\pi^{*}$ is the expected inflation rate for the peso, and a dot over a variable denotes the time derivative.

The optimal conditions are

$$
\begin{gathered}
V_{1} / V_{2}=\left(\pi^{*}+\rho^{*}\right) /\left(\pi+\rho^{*}\right), \\
V_{1}-U^{\prime}\left(c^{*}\right)\left(\pi^{*}+\rho^{*}\right)+U^{\prime \prime}\left(c^{*}\right) \dot{c}^{*}=0, \\
y^{*}+x^{*}-c^{*}-\pi^{*} m^{*}-\pi m_{f}-\dot{m}_{f}-\dot{m}^{*}=0 .
\end{gathered}
$$

The corresponding optimization program for a representative family in the USA is :

$$
\begin{aligned}
& \operatorname{Max} \int_{0}^{\infty} u\left(c, m_{u}\right) e^{-\rho t} d t \\
& \text { s.t. } \dot{m}_{u}=y+x-c-\pi m_{u},
\end{aligned}
$$

where $y, c$, and $m_{u}$ are per capita output, consumption, and real balances in the 
representative family of the USA, $\rho$ is the time discount rate, and $x$ is the government transfer to each family member.

The necessary conditions for optimization are

$$
\begin{gathered}
u_{2}-u_{1}\left(\pi+\rho^{*}\right)+u_{11} \dot{c}+u_{12} \dot{m}_{u}=0, \\
y+x-c-\pi m_{u}-\dot{m}_{u}=0 .
\end{gathered}
$$

Now we turn to the LA and the US governments' money supplies and their transfer to their citizens. For simplicity, we further assume that the population sizes in these two countries are the same: $N=N^{*}$ and $N$ and $N^{*}$ are total population in the USA and LA respectively. Thus the real dollar supply per US citizen is

$$
m=M / p N=\left(M_{u} / p N\right)+\left(M_{f} / p N\right)=m_{u}+\left(M_{f} / p N^{*}\right)\left(N^{*} / N\right)=m_{u}+m_{f} .
$$

By definition,

$$
\begin{aligned}
\dot{m}^{*} & =\left[\theta^{*}-\left(\dot{\mathrm{p}}^{*} / p^{*}\right)\right] m^{*}, \\
\dot{m}_{u} & =\left[\theta_{u}-(\dot{p} / p)\right] m_{u}, \\
\dot{m}_{f} & =\left[\theta_{f}-(\dot{p} / p)\right] m_{f},
\end{aligned}
$$

where $\theta^{*}$ is the peso growth rate in LA, $\theta_{u}$ and $\theta_{f}$ are the dollar growth rates in the USA and LA respectively. With perfect foresight,

$$
\begin{gathered}
\dot{p}^{*} / p^{*}=\pi^{*}, \\
\dot{p} / p=\pi .
\end{gathered}
$$

Substituting $\langle 9\rangle$ and $\langle 10\rangle$ into $\langle 6\rangle,\langle 7\rangle$, and $\langle 8\rangle$ :

$$
\begin{aligned}
& \dot{m}^{*}=\left(\theta^{*}-\pi^{*}\right) m^{*}, \\
& \dot{m}_{u}=\left(\theta_{u}-\pi\right) m_{u}, \\
& \dot{m}_{f}=\left(\theta_{f}-\pi\right) m_{f} .
\end{aligned}
$$

The transfer from LA's government to its citizens is

$$
x^{*}=\theta^{*} m^{*} .
$$

The US government transfer is

$$
x=\theta_{u} m_{u}+\theta_{f} m_{f} .
$$

Substituting $\langle 11\rangle,\langle 12\rangle,\langle 13\rangle,\langle 14\rangle$, and $\langle 15\rangle$ into the dynamic equations $\langle 1\rangle,\langle 2\rangle,\langle 3\rangle,\langle 4\rangle$, and $\langle 5\rangle$ and assuming the steady state (in the steady state, $\dot{c}=\dot{c}^{*}=\dot{m}_{u}=\dot{m}_{f}=\dot{m}^{*}=0$ ), we get :

$$
\begin{gathered}
V_{1} / V_{2}=\left(\theta^{*}+\rho^{*}\right) /\left(\theta+\rho^{*}\right), \\
V_{1}-U^{\prime}\left(c^{*}\right)\left(\theta^{*}+\rho^{*}\right)=0, \\
V_{2}-U^{\prime}\left(c^{*}\right)\left(\theta+\rho^{*}\right)=0, \\
y^{*}-c^{*}-\theta m_{f}=0, \\
u_{2}-u_{1}(\theta+\rho)=0, \\
y-c+\theta m_{f}=0 .
\end{gathered}
$$


One equation out of $\langle 16\rangle$, $\langle 17\rangle$, and $\langle 18\rangle$ is redundant, but we present all here for the convenience of analysis. Equations $\langle 17\rangle$ and $\langle 18\rangle$ are optimal conditions regarding consumption and real balances holdings in LA and equation $\langle 20\rangle$ is the corresponding optimal condition for the USA. These three equations imply that the marginal rates of substitution between real balances and consumption equal the opportunity cost of real balance holdings.

Condition $\langle 16\rangle$ is the optimal condition for currency substitution in LA. It says that the marginal rate of substitution of the two currencies equals the ratio of their costs (the money growth rate plus the time discount rate). This optimal condition suggests that any currency with a high growth rate will be substituted away by the currency with a low inflation rate (suprisingly this is not true as shown in Proposition 1 below), and, in particular, complete dollarization is just a special case when the peso and dollar are perfect substitutes in generating liquidity services, i.e.. if $V\left(m^{*}, m_{f}\right)=V\left(m^{*}+m_{f}\right)$. In this case, $V_{1}=V_{2}$ and complete dollarization will happen in LA so long as the peso inflation rate is higher than the dollar inflation rate. But this kind of perfect substitutability does not exist in the real world and both the peso and dollar are used as a medium of transaction in the countries experiencing dollarization, though the peso has a much higher inflation rate than the dollar. For this reason we will focus on the situation where the peso and dollar are imperfect substitutes.

The steady state budget constraint $\langle 19\rangle$ says that the income in LA is divided between consumption and the cost of dollar holdings. From now on, the cost of dollar holdings, $\theta m_{f}$, will be denoted as $s$, where

$$
s=0 m_{f}
$$

it is the seigniorage collected by the USA. From the steady state budget constraint for the USA - equation $\langle 21\rangle$, it is clear that the seigniorage has been redistributed among US citizens in the form of lump-sum transfers.

We now turn to the condition for dollarization under a flexible exchange rate. Throughout this section, it is assumed that consumption goods are normal and that an increase in income will lead to more consumption in the steady state:

$$
d c^{*} / \mathrm{dy}^{*}>0
$$

which is the same as requiring that

$\langle 22\rangle \Delta=V_{12}^{2}-V_{11} V_{22}+U^{\prime \prime}\left(c^{*}\right) \theta\left\{\left(\theta^{*}+\rho^{*}\right) V_{12}-\left(\theta+\rho^{*}\right) V_{11}\right\}<0$,

because $d c^{*} / d y^{*}=\left[V_{12}^{2}-V_{11} V_{22}\right] / \Delta$ and the numerator is negative as $V($.$) is$ concave.

As for the cross partial derivative, $V_{12}$, it can be positive (cooperant ) or negative (noncooperant) as in Liviatan (1981). Calvo and Rodriguez (1977) and Liviatan (1981) have studied monetary expansion and real exchange rate determination under the assumption that the peso and dollar are cooperant. From Proposition 1 below, it is clear that dollarization will not take place when these two currencies are cooperant.

Proposition 1: If the dollar and peso are cooperant, $V_{12}>0$, and then a high peso inflation reduces both peso and dollar holdings in LA; if the dollar and peso are noncooperant, $V_{12}<0$, and a high peso inflation reduces peso holdings and raises dollar holdings in LA. 
Proof: Totally differentiate the steady state optimal conditions $\langle 17\rangle,\langle 18\rangle$, and $\langle 19\rangle$ :

$\langle 23\rangle \quad\left[\begin{array}{ccc}-U^{\prime \prime}\left(c^{*}\right)\left(\theta^{*}+\rho^{*}\right) & V_{11} & V_{12} \\ -U^{\prime \prime}\left(c^{*}\right)\left(\theta+\rho^{*}\right) & V_{12} & V_{22} \\ -1 & 0 & -\theta\end{array}\right]\left[\begin{array}{c}d c^{*} \\ d m^{*} \\ d m_{f}\end{array}\right]=\left[\begin{array}{c}U^{\prime}\left(c^{*}\right)\left(d \theta^{*}+d \rho^{*}\right) \\ U^{\prime}\left(c^{*}\right)\left(d \theta+d \rho^{*}\right) \\ m_{f} d \theta-d y^{*}\end{array}\right]$.

The determinant of the $3 \times 3$ matrix is given by $\Delta$ in $\langle 22\rangle$, which is negative when consumption is normal goods. From $\langle 23\rangle$,

$$
\begin{aligned}
& \frac{d m^{*}}{d \theta^{*}}=\frac{-U^{\prime}\left(c^{*}\right)}{\Delta}\left[V_{22}+U^{\prime \prime}\left(c^{*}\right) \theta\left(\theta+\rho^{*}\right)\right]<0, \\
& \frac{d m_{f}}{d \theta^{*}}=\frac{U^{\prime}\left(c^{*}\right) V_{12}}{\Delta}>0(<0), \quad \text { if } V_{12}<0\left(V_{12}>0\right), \\
& \frac{d c^{*}}{d 0^{*}}=\frac{-U^{\prime}\left(c^{*}\right) \theta V_{12}}{\Delta}<0(>0) \quad \text { if } V_{12}<0\left(V_{12}>0\right) .
\end{aligned}
$$

The result $\langle 24\rangle$ is true because a higher peso inflation raises the cost of liquidity services from the peso and people will economize their peso holdings. If the dollar and peso are cooperant, $V_{12}>0$, and the reduction of peso holdings following a higher peso inflation will reduce the marginal utility of the liquidity services from the dollar. Hence, dollar holdings will be reduced in this case. From the steady state budget constraint, lower dollar holdings mean lower seigniorage collected by the USA so that people in LA have more income for consumption. This is why consumption in LA will rise following higher peso inflation if the peso and dollar are cooperant.

On the other hand, if the peso and dollar are noncooperant, $V_{12}<0$, and a smaller amount of peso holdings leads to a large marginal utility of liquidity services from the dollar. Thus a higher peso inflation induces people to substitute dollars for pesos. For a given dollar inflation rate, more dollar holdings give rise to a greater inflation tax paid to the USA and less income available for consumption in LA. This explains the signs of changes in dollar holdings and consumption in $\langle 25\rangle$ and $\langle 26\rangle$ when $V_{12}<0$.

Another special case of Proposition 1 is when the peso and dollar are separable in utility: $V_{12}=0$. In this case, equation $\langle 24\rangle$ still holds and the reason for it is the same as before. But higher peso inflation will not alter the steady state dollar holdings and consumption in LA:

$$
d m_{f} / d \theta^{*}=d c^{*} / \mathrm{d} \theta^{*}=0 \quad \text { if } V_{12}=0 .
$$

Peso inflation also affects welfare in the USA. If the peso and dollar are cooperant, a higher peso inflation reduces both peso and dollar holdings in LA and thus lowers the seigniorage collected by the USA. As less income is available for the USA, consumption and real balance holdings will be smaller in the USA. The case of cooperancy between the peso and the dollar leads to just the opposite: higher peso inflation increases dollar holdings and seigniorage collected by the USA; therefore consumption and real balances rise in the USA.

Proposition 2: An increase in the dollar inflation rate always reduces dollar 
holdings in LA; its effects on peso holdings and consumption in LA are ambiguous.

The proof is straightforward by applying Cramer's rule in $\langle 23\rangle$ and obtaining $\mathrm{d} m_{f} / d \theta<0$. The effects on consumption and peso holdings in LA are ambiguous because the seigniorage collected by the USA can increase or decrease when dollar inflation is higher. For example, if higher dollar inflation results in more seigniorage collected by the USA, consumption in LA will decrease. As for the peso holdings, the noncooperancy (cooperancy) between the dollar and peso tends to raise (lower) peso holdings, but a lower income tends to reduce them.

The asymmetry between peso inflation and dollar inflation lies in the fact that, for the representative family in LA, the government's seigniorage from peso inflation is transferred to consumers while the dollar represents a real cost from LA's national standpoint. The steady state budget constraint makes this point very clear.

Next we turn to the discussion of seigniorage collected by the USA. We first extend the usual properties of seigniorage to the case of currency substitution. For the USA, the seigniorage is given by:

$$
s\left(\theta, \theta^{*}\right)=\theta m_{f}\left(\theta, \theta^{*}\right)
$$

which is a function of both the dollar inflation rate and the peso inflation rate. We will assume that the seigniorage can be represented by a Laffer curve, namely, that there exists a positive inflation rate $\bar{\theta}$ such that $\partial s / \partial \theta$ is positive for $\theta<\bar{\theta}$ and negative for $\theta>\bar{\theta}$; and $\partial^{2} s / \partial \theta^{2}<0$.

With currency substitution, we know that, from Proposition $1, \partial s / \partial \theta^{*}$ is positive if the two currencies are noncooperant and it is negative if the two currencies are cooperant. Furthermore it is reasonable to have

Assumption 1: $\partial^{2} s / \partial \theta^{*} \partial \theta>0$ if the peso and the dollar are noncooperant and $\partial^{2} s / \partial \theta^{*} \partial \theta<0$ if the peso and the dollar are cooperant.

For the case of noncooperancy, a small increase in dollar inflation following a higher peso inflation should not reduce dollar holdings too much in LA, stated in terms of the following expression,

$$
\partial^{2} s / \partial \theta^{*} \partial \theta=\theta\left(\partial^{2} m_{f} / \partial \theta \partial \theta^{*}\right)+\left(\partial m_{f} / \partial \theta^{*}\right)
$$

the first term (cross effect) should not be so negative as to dominate the second term (direct effect), which is positive for the noncooperant case. For the case of cooperancy, the second term is negative. We will expect this direct effect to dominate the cross effect no matter whether the cross effect is positive or negative.

With the Laffer curve assumption and assumption 1, it is simple to see how the dollar inflation rate should respond to peso inflation if the USA attempts to maximize the inflation tax from LA. The first-order condition is the familiar one:

$$
\partial s / \partial \theta=m_{f}+\theta\left(\partial m_{f} / \partial \theta\right)=0 \text {. }
$$

Totally differentiating this equation yields :

$$
\frac{d \theta}{d \theta^{*}}=\frac{-\left(\partial^{2} s / \partial \theta \partial \theta^{*}\right)}{\partial^{2} s / \partial \theta^{2}} .
$$


Therefore, if the two currencies are noncooperant,

$$
d \theta / d \theta^{*}>0 \text {. }
$$

But if the dollar and peso are cooperant,

$$
d \theta / d \theta^{*}<0 .
$$

That is to say, if the peso and dollar are noncooperant, an increase in peso inflation leads people in LA to switch to more dollar holdings, and the USA can collect more seigniorage by raising dollar inflation. If these two currencies are cooperant, high peso inflation reduces both peso and dollar holdings and, hence, when peso inflation is high, the dollar inflation rate should be reduced in order to avoid more loss of seigniorage income from LA.

\section{Government inflation finance in LA and the determination of the peso and dollar inflation rates}

In the real world, dollarization is often observed in those countries in which inflation finance is the main instrument used to raise revenue for government spending. When inflation finance by LA's government is taken into consideration in the representative family model, the budget constraint becomes

$$
\begin{aligned}
& \dot{a}^{*}=y^{*}-c^{*}-\pi m_{f}-\pi^{*} m^{*}, \\
& a^{*}=m_{f}+m^{*} .
\end{aligned}
$$

So the government transfer, $x^{*}$, is set to be zero.

The new steady state equilibrium conditions are

$$
\begin{aligned}
V_{1}-U^{\prime}\left(c^{*}\right)\left(\theta^{*}+\rho^{*}\right) & =0, \\
V_{2}-U^{\prime}\left(c^{*}\right)\left(\theta+\rho^{*}\right) & =0, \\
y^{*}-c^{*}-\theta^{*} m^{*}-\theta m_{f} & =0 .
\end{aligned}
$$

If we denote the peso inflation tax by $s^{*}\left(\theta^{*}, \theta\right)$, then from $\langle 27\rangle$,

$$
s^{*}\left(\theta^{*}, \theta\right)=\theta^{*} m^{*}\left(\theta^{*}, \theta\right) .
$$

In this new setting, both dollar and peso inflation are real tax burdens on the representative family in LA and the asymmetric roles of dollar and peso inflation in Section III disappear here. As we have seen from Proposition 1, the case of cooperancy between the dollar and peso does not impose a serious constraint on LA's government inflation finance because a high peso inflation tends to reduce both peso and dollar holdings, and dollarization may not necessarily happen in LA even though the peso inflation is high. Therefore, we will focus on the case in which the peso and dollar are noncooperant and, unless otherwise noted, it will be assumed throughout this section that $V_{12}<0$.

To understand the connection between the LA government's inflation finance and dollarization, we first note that, if the stream of liquidity services from peso holdings is a normal consumption good, peso holdings will be reduced following high peso inflation: $\partial m^{*} / \partial \theta^{*}<0$. But the seigniorage $s^{*}=\theta^{*} m^{*}$ may go up or 
down. If $s^{*}$ goes down for a higher peso inflation rate, we have the following strong result :

Proposition 3: If the peso inflation tax is given by a Laffer curve, then, for a given dollar inflation rate $\theta$, there exists a critical peso inflation rate $\bar{\theta}^{*}$ such that dollarization will always take place for $\theta^{*}>\bar{\theta}^{*}$; and $\bar{\theta}^{*}$ is determined by the equation $\partial s^{*} / \partial \theta^{*}=0$.

Proof: Since $s^{*}\left(\theta^{*}, \theta\right)$ is a Laffer curve, we have, for a given $\theta$, a unique $\bar{\theta}^{*}$ satisfying the equation $\partial s^{*}\left(\bar{\theta}^{*}, \theta\right) / \partial \theta^{*}=0$ and $\partial s^{*} / \partial \theta^{*}>0$ for $\theta^{*}<\bar{\theta}^{*}$ and $\partial s^{*} / \partial 0^{*}<0$ for $\theta^{*}>\bar{\theta}^{*}$.

Now consider the case: $\theta^{*}>\bar{\theta}^{*}$ and $\partial s^{*} / \partial \theta^{*}<0$. Differentiating the steady state budget constraint $\langle 27\rangle$ with respect to the peso inflation rate $\theta^{*}$ :

$$
\partial c^{*} / \partial \theta^{*}+0 \partial m_{f} / \partial \theta^{*}=-\partial s^{*} / \partial \theta^{*} \text {. }
$$

The right-hand side of $\langle 28\rangle$ is positive as $\partial s^{*} / \partial \theta^{*}$ is negative for $\theta^{*}>\bar{\theta}^{*}$. The left-hand side can be written as (via conditions $\langle 18\rangle$ ):

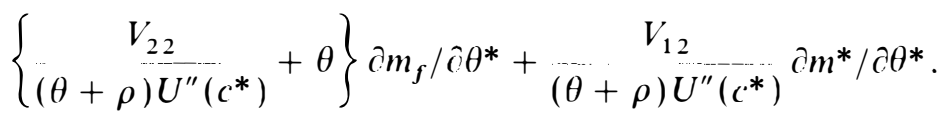

In $\langle 29\rangle$, the second term is negative for $V_{12}<0, \partial m^{*} / \partial \theta^{*}<0$ and $U^{\prime \prime}<0$. The coefficient of $\partial m_{f} / \partial \theta^{*}$ is positive. Therefore, to have equation $\langle 28\rangle, \partial m_{f} / \partial \theta^{*}$ has to be positive; that is to say, when $\theta^{*}>\bar{\theta}^{*}$, dollarization definitely takes place. Q.E.D.

The economic explanation for this result is the following: If the peso inflation rate is higher than the seigniorage maximizing rate $\bar{\theta}^{*}$, seigniorage income from further peso inflation will be reduced and the public will have more income available for both consumption and dollar holdings. This income effect of dollar holdings will be further reinforced by the substitution effect - high peso inflation directly reduces peso demand and increases the attractiveness of the dollar when the peso and dollar are noncooperant. Therefore, dollarization will definitely happen on the wrong side of the Laffer curve and LA's government in this situation can reduce its national loss and, at the same time, raise more inflation tax by lowering the peso inflation rate.

What will happen if the peso inflation is below the critical level $\bar{\theta}^{*}$ ? As we have pointed out, $s^{*}$ is rising for $\theta^{*}<\bar{\theta}^{*}$ and people in LA will end up with less income for a higher peso inflation. Though a high peso inflation rate induces people in LA to substitute the dollar for peso holdings, the income effect may dominate the substitution effect and dollar holdings may also be reduced. If the substitution effect dominates the income effect, dollarization will take place for $\theta^{*}<\bar{\theta}^{*}$. It is often stated that the LA government can do better without causing dollarization. For LA's national interest, this is absolutely right. But for LA's government, keeping a very low peso inflation and avoiding dollarization may result in a significant loss of government revenue. This is especially true here because dollarization happens at the same time that the peso inflation tax collected by LA's government is rising.

Our model also provides us with a coherent general equilibrium framework that we can use to study inflation determination for different currencies. The endogenization of both peso and dollar inflation is an improvement over the 
models studying only the country experiencing dollarization. In the following, we will show how seigniorage maximization by LA's government and how welfare or seigniorage maximization by the US government lead to the equilibrium peso and dollar inflation rates. We begin with LA.

Suppose that LA's government intends to maximize its seigniorage from its citizens given the possibility that its people can substitute the dollar for the peso. Obviously its choice of proper peso inflation $\theta^{*}$ depends on the dollar inflation rate $\theta$. In the special case where the peso and dollar are perfect substitutes in generating liquidity services, i.e., $V\left(m^{*}, m_{f}\right)=V\left(m^{*}+m_{f}\right)$, people in LA will be indifferent between holding pesos or dollars if they have the same inflation rate. If the peso inflation rate is higher than the dollar inflation rate, as we mentioned earlier, there will be complete dollarization and LA government's seigniorage from peso inflation will be zero. Therefore, in this case, the optimal strategy for LA's government is to set the peso inflation rate such that it is less than or equal to the dollar inflation rate.

In the more general case in which the peso and dollar are imperfect substitutions, it is quite reasonable to assume as in Proposition 3 that the peso inflation tax collected by LA's government is given by the usual Laffer curve and that higher peso inflation accompanied by higher dollar inflation should not reduce seigniorage collected by LA's government:

Assumption 2: $\partial^{2} s / \partial \theta^{*} \partial \theta>0$.

Again, due to the Laffer curve properties of $s^{*}\left(\theta^{*}, \theta\right)$, the necessary and sufficient condition for maximizing $s^{*}\left(\theta^{*}, \theta\right)$ by choosing $\theta^{*}$ (given $\theta$ ) is

$$
\partial s^{*}\left(\theta^{*}, \theta\right) / \partial \theta^{*}=m^{*}+\theta^{*}\left(\partial m^{*} / \partial \theta^{*}\right)=0 .
$$

With assumption 2, it is simple to see

$$
d \theta^{*} / d \theta=-\left(\partial^{2} s^{*} / \partial \theta^{*} \partial \theta\right) /\left(\partial^{2} s^{*} / \partial \theta^{* 2}\right)>0 .
$$

Hence lower peso inflation should follow lower dollar inflation and the dollar inflation rate sets a constraint on how much the government in LA can collect from the public through peso inflation. It is simple to see that the seigniorage maximizing peso inflation rate with dollarization should be smaller than the one without dollarization in LA. This can be easily seen. Imagine that there is a hyperinflation in the USA. For this extreme case, dollarization will not take place in LA. By $\langle 31\rangle$, LA's government can choose a much higher peso inflation rate in this situation than in the case of a moderate or small dollar inflation. But, in practice, governments in the dollarized countries may not pay enough attention to the dollar inflation rate when choosing their national currencies' inflation rates. The consequences of their actions are further dollarization and less inflation tax.

To determine dollar inflation and its relation to peso inflation, we continue to assume as in the last section that $s\left(\theta, \theta^{*}\right)$ is a Laffer curve and assumption 1 still holds. Given peso inflation $\theta^{*}$, two options are available for the USA to determine the dollar inflation rate. The first is welfare maximization:

$$
\begin{aligned}
\partial u / \partial \theta & =u_{1} \partial c / \partial \theta+u_{2} \partial m_{u} / \partial \theta \\
& =u_{1} \partial s / \partial \theta+u_{2} \partial m_{u} / \partial \theta=0
\end{aligned}
$$


This is the same as requiring that, by solving $\partial m_{u} / \partial \theta$ from $\langle 20\rangle$ and $\langle 21\rangle$,

$$
\left[u_{11}(\theta+\rho)-u_{12}+(\theta+\rho) b\right](\partial s / \partial \theta)=-u_{1},
$$

here

$$
b=u_{22}-u_{12}(\theta+\rho)<0 .
$$

The term in the bracket on the left side of $\langle 32\rangle$ is negative, and the term on the right side is also negative, so at the optimum,

$$
\hat{\partial} / \partial \theta>0 \text {. }
$$

Therefore, the welfare maximizing dollar inflation rate chosen by the US government lies at the increasing part of the Laffer curve and, for a given peso inflation rate, it is smaller than the seigniorage maximizing one. This is because dollar inflation has two effects: it directly reduces consumer welfare in the USA and it may increase or decrease the seigniorage collected from LA. At the optimum, the direct welfare loss due to dollar inflation has to be compensated by the additional income raised by the dollar inflation.

The second option for the USA is to maximize its seigniorage collected from LA :

$$
\partial s\left(\theta, \theta^{*}\right) / \partial \theta=m_{f}+\theta\left(\partial m_{f} / \partial \theta\right)=0 .
$$

Now $\langle 30\rangle$ and $\langle 33\rangle$ will jointly determine the peso and dollar inflation rates. Since the seigniorage maximizing dollar inflation rate is higher than the welfare maximizing one and a higher dollar inflation leads to a higher peso inflation rate by $\langle 31\rangle$, seigniorage maximization by both governments leads to both higher peso and dollar inflation.

So far our discussion of peso and dollar inflation has been limited to the Nash equilibria. What does our model tell us about the USA as a leader and LA as a follower in a Stackelberg game of seigniorage maximization? Using $\langle 30\rangle$, the peso inflation rate can be written as an increasing function of the dollar inflation rate: $\theta^{*}=\theta^{*}(\theta)$ and $d \theta^{*} / \mathrm{d} \theta>0$. The USA maximizes $s\left(\theta, \theta^{*}(\theta)\right)$ by choosing $\theta$. The first-order condition is

$$
\partial s / \partial \theta+\left(\partial s / \partial \theta^{*}\right)\left(d \theta^{*} / \partial \theta\right)=0 .
$$

The first term on the left-hand side of $\langle 34\rangle$ is the direct gain or loss in seigniorage through an increase in the dollar inflation rate and the second term is the indirect gain or loss in seigniorage through the effect of dollar inflation on peso inflation. These two effects offset each other when the seigniorage is maximized.

Comparing equilibrium condition $\langle 34\rangle$ to $\langle 33\rangle$, we have

Proposition 4: The Stackelberg equilibrium rates of the peso and dollar inflation are higher than the Nash equilibrium rates if peso inflation leads to more dollar holdings in LA.

Proof: The conditions for both Nash and Stackelberg equilibrium are:

$$
\begin{gathered}
\partial s\left(\theta^{n}, \theta^{*}\left(\theta^{n}\right)\right) / \partial \theta=0, \\
\left.\partial s\left(\theta^{s}, \theta^{*}\left(\theta^{s}\right)\right) / \partial \theta+\left(\partial s\left(\theta^{s}, \theta^{*}\left(\theta^{s}\right)\right) / \partial \theta^{*}\right)\right)\left(d \theta^{*} / d \theta\right)=0,
\end{gathered}
$$

where $\theta^{n}$ and $\theta^{s}$ denote the dollar inflation rates for Nash and Stackelberg equilibria respectively, and $\theta^{*}(\theta)$ is LA's government reaction function solved 
from the condition $\langle 30\rangle$ and again $d \theta^{*} / d \theta$ is positive (namely, high dollar inflation leads to high peso inflation ).

If peso inflation results in more dollar holdings, there will be more seigniorage income for the USA and $\partial s / \partial \theta^{*}$ in $\left\langle 34^{\prime}\right\rangle$ will be positive. Hence, $\partial s / \partial \theta$ on the left-hand side of $\left\langle 34^{\prime}\right\rangle$ (the Stackelberg equilibrium condition ) has to be negative. But from the condition for the Nash equilibrium $\left\langle 33^{\prime}\right\rangle, \partial s / \partial \theta=0$. We must show that $\theta^{s}$ is larger than $\theta^{n}$ in this case.

Taking a Taylor expansion of $\partial s\left(\theta^{s}, \theta^{*}\left(\theta^{s}\right)\right) / \partial \theta$ at the Nash equilibrium value yields :

$$
\begin{aligned}
0>\partial s\left(\theta^{s}, \theta^{*}\left(\theta^{s}\right)\right) / \partial \theta= & \partial s\left(\theta^{n}, \theta^{*}\left(\theta^{n}\right)\right) / \partial \theta+\left(\theta^{s}-\theta^{n}\right) \partial^{2} s\left(\phi^{\varphi}, \theta^{*}\left(\theta^{\varphi}\right)\right) / \partial \theta^{2} \\
& +\left(\theta^{s}-\theta^{n}\right)\left(\partial^{2} s\left(\theta^{\varphi}, \theta^{*}\left(\theta^{\varphi}\right)\right) / \partial \theta \partial \theta^{*}\right) d \theta^{*}\left(\theta^{\varphi}\right) / d \theta \\
= & \left(\theta^{s}-\theta^{n}\right) \partial^{2} s\left(\theta^{\varphi}, \theta^{*}\left(\theta^{\varphi}\right)\right) / \partial \theta^{2} \\
& +\left(\theta^{s}-\theta^{n}\right)\left(\partial^{2} s\left(\theta^{\varphi}, \theta^{*}\left(\theta^{\varphi}\right)\right) / \partial \theta \partial \theta^{*}\right) d \theta^{*}\left(\theta^{\varphi}\right) / d \theta
\end{aligned}
$$

where $\theta^{\varphi}$ is between $\theta^{s}$ and $\theta^{n}$. Suppose that $\theta^{s}<\theta^{n}$. The stability condition for Nash equilibrium is

$$
d \theta^{*}\left(\theta^{\varphi}\right) / d \theta=-\frac{\partial^{2} s^{*} / \partial \theta \partial \theta^{*}}{\partial^{2} s^{*} / \partial \theta^{* 2}}<-\frac{\partial^{2} s / \partial \theta^{2}}{\partial^{2} s / \partial \theta \partial \theta^{*}} .
$$

Substitute $d \theta^{*} / d \theta$ into $\langle 35\rangle$ and note that $\theta^{s}<\theta^{n}$ and $\partial^{2} s / \partial \theta / \partial \theta^{*}>0$ by assumption :

$$
\begin{aligned}
0> & \partial s\left(\theta^{s}, \theta^{*}\left(\theta^{s}\right)\right) / \partial \theta \\
= & \left(\theta^{s}-\theta^{n}\right) \partial^{2} s\left(\theta^{\varphi}, \theta^{*}\left(\theta^{\varphi}\right)\right) / \partial \theta^{2}+\left(\theta^{s}-\theta^{n}\right)\left(\partial^{2} s\left(\theta^{\varphi}, \theta^{*}\left(\theta^{\varphi}\right)\right) / \partial \theta \partial \theta^{*}\right) d \theta^{*}\left(\theta^{\varphi}\right) / d \theta \\
> & \left(\theta^{s}-\theta^{n}\right) \partial^{2} s\left(\theta^{\varphi}, \theta^{*}\left(\theta^{\varphi}\right)\right) / \partial \theta^{2} \\
& \quad+\left(\theta^{s}-\theta^{n}\right)\left(\partial^{2} s\left(\theta^{\varphi}, \theta^{*}\left(\theta^{\varphi}\right)\right) / \partial \theta \partial \theta^{*}\right)\left(-\frac{\partial^{2} s / \partial \theta^{2}}{\partial^{2} s / \partial \theta \partial \theta^{*}}\right) \\
& =0 .
\end{aligned}
$$

This is a contradiction because $\partial s / \partial \theta$ cannot be less than zero and larger than zero at the same time. Therefore, if peso inflation leads to more dollar holdings, the dollar inflation for Stackelberg equilibrium will be higher than the one for Nash equilibrium : $\theta^{s}>\theta^{n}$. Since $d \theta^{*} / d \theta$ is positive, the peso inflation rate is also higher.

The economic intuition for this proposition is quite clear. As higher dollar inflation induces higher peso inflation and higher peso inflation forces people in LA to hold more dollars, the USA can collect a higher inflation tax from LA by recognizing its leading position in the Stackelberg game and setting a higher dollar inflation rate than in the Nash equilibrium.

\section{Summary}

In a two-country model, this paper has provided insight into two aspects of dollarization. 
First, if the government in LA transfers its inflation tax to the public, dollarization will only happen when two currencies are noncooperant in generating liquidity service (Proposition 1); if the government finances its spending by inflation tax, dollarization will definitely occur on the wrong side of the Laffer curve (Proposition 3 ).

Second, if seigniorage maximization is the objective of LA's government, unintended dollarization may be an inevitable consequence of government policy because under certain circumstances more seigniorage income and further dollarization can occur at the same time. Nevertheless, the choice of proper peso inflation rates by LA's government crucially depends on the strategic choices of the dollar inflation. In particular, if the US government maximizes its citizens' welfare, the expected dollar inflation will be moderate and so is the seigniorage maximizing peso inflation rate. If both governments maximize their inflation tax independently, the resulting peso and dollar inflation rate are likely to be high. When there exists strategic interdependence, the seigniorage maximizing peso and dollar inflation rates for the Stackelberg equilibrium are higher than the ones for the Nash equilibrium (Proposition 4 ).

\section{References}

Calve, G., AND C. Rodriguez, 'A Model of Exchange Rate Determination under Currency Substitution and Rational Expectations,' Journal of Political Economy, June 1977, 85: $617-625$.

Fischer, S., 'Seigniorage and the Case for a National Money,' Journal of Political Economy, April 1982, 90: 295--313.

FisCHER, S., 'Seigniorage and Fixed Exchange Rates: An Optimal Inflation Tax Analysis,' in Aspe Armella et al., eds, Financial Policies and the World Capital Markets: The Prohlem of Latin American Countries, University of Chicago Press, 1983.

Lamdany, R., AND Jorge Dorlhiac, 'The Dollarization of a Small Economy,' Scandinavian Journal of Economics, March 1987, 89: 91-102.

Liviatan, N.. 'Monetary Expansion and Real Exchange Rate Dynamics,' Journal of Political Economy, December 1981, 89: 1218-1227.

Ortiz, G., 'Dollarization in Mexico: Causes and Consequences,' in Aspe Armella et al., eds, Financial Policies and the World Capital Markets: The Problem of Latin American Countries, University of Chicago Press, 1983.

Stockman, A., 'Risk. Information, and Forward Exchange Rates,' in J. Frenkel and H. Johnson, eds, The Economic's of Exchange Rates, Reading, Mass. : Addison-Wesley, 1978. 